CLINICAL STUDY

\title{
Born with low birth weight in rural Southern India: what are the metabolic consequences 20 years later?
}

\author{
Nihal Thomas ${ }^{1,2, *}$, Louise G Grunnet ${ }^{3, *}$, Pernille Poulsen ${ }^{4}$, Solomon Christopher ${ }^{5}$, Rachaproleu Spurgeon ${ }^{1}$, \\ Mercy Inbakumari ${ }^{1}$, Roshan Livingstone ${ }^{6}$, Reginald Alex ${ }^{7}$, Venkataraghava R Mohan ${ }^{7}$, Belavendra Antonisamy ${ }^{5}$, \\ Finney S Geethanjali ${ }^{8}$, Rajni Karol ${ }^{9}$, Allan Vaag ${ }^{3}$ and Ib C Bygbjerg ${ }^{2}$ \\ ${ }^{1}$ Department of Endocrinology, Diabetes and Metabolism, Christian Medical College, Vellore (CMC), India, ${ }^{2}$ Department of International Health, \\ Immunology and Microbiology, University of Copenhagen, Copenhagen, Denmark, ${ }^{3}$ Diabetea and Metabolism Rigshospitalet, Tagensvej 20,2200 \\ Copenhagen N, Denmark, ${ }^{4}$ Medical and Science GLP-1 Development, Novo Nordisk A/S, Denmark, Departments of ${ }^{5}$ Biostatistics, ${ }^{6}$ Radiodiagnosis, \\ ${ }^{7}$ Community Health, ${ }^{8}$ Biochemistry and ${ }^{9}$ Dietary Department, Christian Medical College, Vellore (CMC), India \\ (Correspondence should be addressed to L G Grunnet; Email: louise.groth.grunnet@rh.regionh.dk)
}

*(N Thomas and L G Grunnet contributed equally to this work)

\begin{abstract}
Objective: Low birth weight (LBW) is common in the Indian population and may represent an important predisposing factor for type 2 diabetes (T2D) and the metabolic syndrome. Intensive metabolic examinations in ethnic LBW Asian Indians have been almost exclusively performed in immigrants living outside India. Therefore, we aimed to study the metabolic impact of being born with LBW in a rural non-migrant Indian population.

Subjects and methods: One hundred and seventeen non-migrant, young healthy men were recruited from a birth cohort in a rural part of south India. The subjects comprised $61 \mathrm{LBW}$ and 56 normal birth weight (NBW) men, with NBW men acting as controls. Subjects underwent a hyperinsulinaemic euglycaemic clamp, i.v. and oral glucose tolerance tests and a dual-energy X-ray absorptiometry scan. The parents' anthropometric status and metabolic parameters were assessed.

Results: Men with LBW were shorter $(167 \pm 6.4$ vs $172 \pm 6.0 \mathrm{~cm}, P<0.0001)$, lighter $(51.9 \pm 9$ vs $55.4 \pm 7 \mathrm{~kg}, P=0.02)$ and had a reduced lean body mass $(42.1 \pm 5.4$ vs $45.0 \pm 4.5 \mathrm{~kg}, P=0.002)$ compared with NBW controls. After adjustment for height and weight, the LBW subjects had increased diastolic blood pressure $(77 \pm 6$ vs $75 \pm 6 \mathrm{mmHg}, P=0.01)$. Five LBW subjects had impaired glucose tolerance. In vivo insulin secretion and peripheral insulin action were similar in both the groups. Mothers of the LBW subjects were $3 \mathrm{~cm}$ shorter than the control mothers.

Conclusion: Only subtle features of the metabolic syndrome and changes in body composition among LBW rural Indians were found. Whether other factors such as urbanisation and ageing may unmask more severe metabolic abnormalities may require a long-term follow-up.
\end{abstract}

European Journal of Endocrinology 166 647-655

\section{Introduction}

The prevalence of pre-diabetes and diabetes is increasing worldwide with India being among the top three most affected countries. The epidemic of diabetes has mainly been brought about through a complex interplay between demographic, nutritional and economic transitions (1).

Previous studies have demonstrated that south Asians are more prone to develop insulin resistance, hypertension and coronary artery disease when compared with the Western population (2). Furthermore, the Indian patient with type 2 diabetes (T2D) tends to be diagnosed a decade earlier, is characterised by a lower body mass index (BMI) and is more centrally obese when compared with patients of Caucasian origin (3). Additionally, non-diabetic south Asians are more insulin resistant $(4,5)$ and have an adverse fat distribution with more abdominal, hepatic and intramyocellular fat $(6,7)$ when compared with those from other ethnic groups with a similar BMI.

Studies over the last two decades have now confirmed an association between low birth weight (LBW) and the risk of developing T2D later in life (8). The prevalence of LBW is significantly higher in India when compared with many other countries with approximately as many as $30 \%$ of infants being born underweight (birth weight $<$ $2500 \mathrm{~g}$ ), predominantly owing to under-nutrition of the mother before and during pregnancy (9). LBW among Indians compared with Caucasians has been proposed to constitute a 'thin-fat phenotype' predisposing Indians to 
T2D and the metabolic syndrome. A study has shown that Indian babies born with LBW preserve body fat and reduce muscle mass during their intrauterine development compared with normal birth weight (NBW) babies (10). Insulin resistance represents a hallmark in the pathophysiology of T2D, and LBW as well as an increased fat mass are associated with an increased risk of developing insulin resistance. The hyperinsulinaemic euglycaemic clamp is the gold standard for measuring insulin resistance. However, except for a single pilot study (11), the hyperinsulinaemic euglycaemic clamp assessment has only been applied to migrant Asian Indians living outside India, who were older and had a significantly higher BMI. Moreover, previous studies on insulin actions among Indian LBW subjects have used indirect methods to assess insulin sensitivity.

The aims of this study were to investigate the anthropometric and metabolic characteristics, including body composition, insulin secretion and insulin action, among young healthy rural Indians to identify the native Indian LBW phenotype unaffected by urbanisation and Westernisation. The parents were traced and studied to address the potential role of the intergenerational transmission of the adult LBW-associated traits.

\section{Study design and population}

\section{Ethics statement}

The protocol was approved by the local ethics committee: the Institutional Review Board of Christian Medical College, Vellore, India (Research Committee Minute Number: 5879, 2006 and Administrative Committee Minute Number: 50-y: 6-2006). All patients gave their informed written consent in the local language.

One hundred and seventeen healthy males participated in the study. They were selected according to their birth weight from the birth registry at the Christian Medical College, Vellore, India. The Community Health and Development (CHAD) programme run by the Department of Community Health, Christian Medical College, Vellore provides primary and secondary health care services to all the 82 villages in Kaniyambadi, a rural development block in the Vellore district located in Southern India. The CHAD programme has in place an ongoing surveillance system where information on pregnancies, deliveries, births, deaths, morbidity and immunisation status among mothers are recorded and updated in the Health Information System. All men were born between 1986 and 1990 in a rural area in the south Indian state of Tamil Nadu, in north Arcot district, near the town of Vellore in the Kaniyambadi block and belonged to Dravidian ethnicity. The Dravidians are found particularly in Southern India and comprise about $20 \%$ of the Indian population (12). Thus, the results from this study can be applied to a significant non-Caucasian proportion of the Indian people and form a particularly useful reference database in relation to other south Indian studies. Moreover, this was a homogenous rural population that did not have the cosmopolitan ethnicity and urban influence, that previous studies have had. According to the definition of the term 'rural', in this study the population was sourced from the parts of a region that did not have a clustered population in excess of 50000 living in a market town and a designated population of $<999$ per square mile.

The birth cohort for the years 1986-1992 comprised 13172 individuals with 922.4 females per 1000 males. The 10th, 70th and 90th percentiles for birth weights in this cohort were $2.45,3.10$ and $3.50 \mathrm{~kg}$ respectively. All the males who were born with LBW $(<10$ th percentile) and NBW (70-90th percentiles) were identified from 23 randomly selected villages and their families were met. The families of 265 eligible subjects were interviewed, and the subjects were subsequently traced of whom 117 participated in the study. The main reasons for non-participation were migration, holding a job elsewhere and unwillingness to participate.

Sixty-one men had LBW (birth weight $\leq 10$ th percentile, $\sim$ birth weight $<2450$ g) and 56 were born with NBW ( $\geq 70$ th percentile and $<90$ th percentile, birth weight $\geq 3100$ and $<3500 \mathrm{~g}$ respectively). Subjects with a BMI $>30 \mathrm{~kg} / \mathrm{m}^{2}$, heavy alcohol or tobacco misuse, medication known to interfere with glucose metabolism and acute and/or chronic diseases were excluded from the study.

The purpose of the study and the potential risks involved were explained to each of the subjects by a local social worker and reinforced by the doctor and the study nurse, and a written informed consent was signed before study participation. Parents were invited for a medical examination that included a screening assessment for diabetes. Information regarding the socioeconomic status of the families was obtained from the CHAD SES scoring scale as described previously (13) based on caste, type of house, land owned in acres, educational level of the head of household and occupation of the head of household. Figure 1 shows a flow chart with the pattern of recruitment and clinical examination of the subjects. The birth weight of the invited subjects who were not willing to participate was similar to the birth weight of the participating subjects: LBW: $2140 \pm 260 \mathrm{~g}$ vs $2115 \pm 246 \mathrm{~g}, P=0.74$, and NBW: $3230 \pm 115 \mathrm{~g}$ vs $3215 \pm 122 \mathrm{~g}, P=0.29$.

\section{Procedures}

All subjects underwent a 2-day clinical examination. After an overnight fast, the subjects were escorted from their homes by a social worker to the hospital. They underwent a thorough physical examination that included measurements of weight, height, waist circumference, skinfold thickness and blood pressure. 


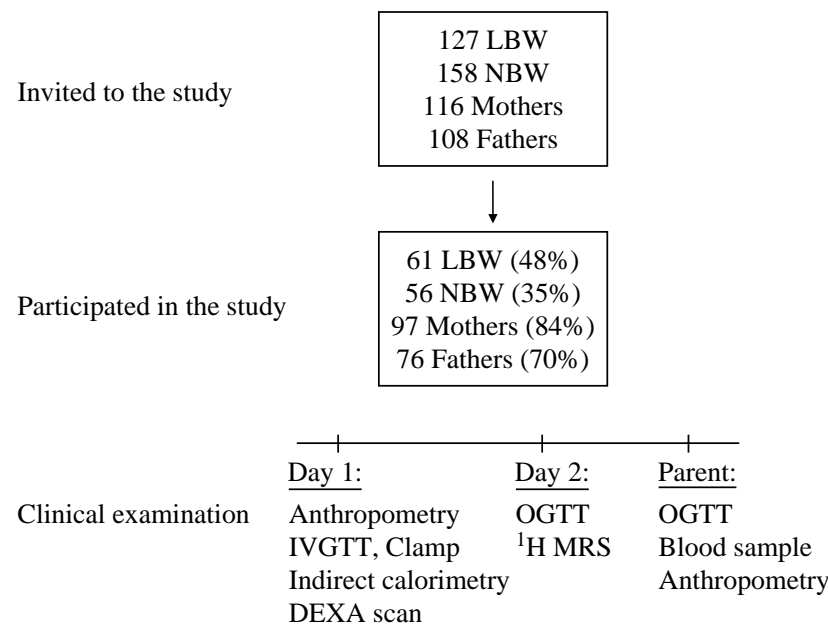

Figure 1 Flow chart of the recruitment process, participation rate and clinical examinations. ${ }^{1}$ Data from H-MRS are not shown in this study.

Hyperinsulinaemic euglycaemic clamp, indirect caloriemetry and i.v. glucose tolerance tests On day 1 , a $2 \mathrm{~h}$ hyperinsulinaemic euglycaemic clamp was performed to determine peripheral insulin sensitivity (14). A polyethylene catheter was placed in the antecubital vein for blood sampling. A second catheter was placed in the ante-cubital vein of the contralateral arm for test infusions. Blood samples for measurements of plasma insulin, C-peptide and glucose were drawn at baseline and at the beginning and end of the steady-state periods. Steady state was defined as the last $30 \mathrm{~min}$ of the basal and the insulin clamp period. To determine $\beta$-cell function, a $30 \mathrm{~min}$ i.v. glucose tolerance test (IVGTT) was initiated after the basal period. A glucose bolus of $0.3 \mathrm{~g} / \mathrm{kg}$ body weight was infused over $1 \mathrm{~min}$. After the IVGTT, a primed-continuous insulin infusion was initiated and fixed at $40 \mathrm{mU} / \mathrm{m}^{2}$ per min during the 160 min clamp. During the clamp, a $25 \%$ glucose solution was infused at a variable rate, adjusted every $5 \mathrm{~min}$ in order to maintain a predetermined plasma glucose concentration of $5 \mathrm{mmol} / \mathrm{l}$. Oxygen consumption $\left(\mathrm{VO}_{2}\right)$, carbon dioxide production $\left(\mathrm{VCO}_{2}\right)$ and respiratory quotient were measured during both basal and insulinstimulated steady state using indirect calorimetry.

Glucose was measured by the glucose oxidaseperoxidase method using reagents supplied by Roche, on Roche Modular P 800 system (\% CV 3.6). Insulin and C-peptide were measured by chemiluminescence Immunoassay, using kits supplied by Siemens, on the Immulite 2000 system (Siemens healthcare Diagnostic products Ltd., Llanberis, Gwynedd, UK). Chemistry and Immunoassay controls supplied by Bio-Rad were used as internal precision controls (\% CV 10.2 for insulin and 3.7 for C-peptide).

Oral glucose tolerance test On day 2, a standardised $75 \mathrm{~g}$ oral glucose tolerance test (OGTT) was performed after an overnight fast at the hospital to determine the glucose tolerance status of the participants. Classification of glucose tolerance status was performed according to the American Diabetes Association (ADA) criteria with diabetes classified as a fasting plasma glucose $\geq 7.0 \mathrm{mmol} / \mathrm{l}$ or $2 \mathrm{~h}$ plasma glucose $\geq 11.1 \mathrm{mmol} / \mathrm{l}$ and impaired glucose tolerance (IGT) between $\geq 7.8$ and $<11.1 \mathrm{mmol} / \mathrm{l}$.

Dual-energy $X$-ray absorptiometry scanning On day 1 , body composition was assessed by dual-energy X-ray absorptiometry (DEXA; QDR 4500; Hologic, Inc., Waltham, MA, USA) giving estimates of total adipose tissue, lean tissue and bone mineral density and the distribution of these components in different body compartments. The DEXA scan was always performed in the fed state after a meal.

Demographic and diet-related data Collection of the demographic data included the age, educational qualifications, family size, type of family and monthly family income. A food and nutrient intake schedule was formulated to obtain the nutrient intake of the subjects, including usual meal pattern, 24-h recall using standardised vessels and the food frequency questionnaire as well as interviews about the type of food according to the meal patterns (for instance the breakfast, lunch, tea and dinner during the previous $24 \mathrm{~h}$ ). The nutrient intake was calculated using food composition tables developed by the National Institute of Nutrition, Indian Council of Medical Research (15).

Examinations of the parents All the parents of the subjects were invited to a clinical examination including an OGTT, anthropometric measurements and fasting blood samples to determine the lipid profile.

Calculations The total insulin-stimulated glucose disposal ( $M$ value) was calculated as the mean glucose infusion during the steady-state period. First-phase insulin secretion (FPIR) during the IVGTT was calculated as the incremental area under the curve (AUC) for insulin during the first $10 \mathrm{~min}$ of the IVGTT using the trapezoidal rule. $\mathrm{AUC}_{\mathrm{insulin}} / \mathrm{AUC}_{\text {glucose }}$ was calculated as a measurement of insulin secretion in relation to the glucose level (PHI-1). The disposition index (Di), i.e. the product of FPIR and peripheral sensitivity, can be calculated because of an approximately hyperbolic relationship between the two measures so that the product is constant for individuals with the same degree of glucose tolerance (16). Di was calculated as PHI- $1 \times M$ value. Oxygen consumption and glucose and fat oxidation rates were calculated as described previously in (17) as: glucose oxidation: $4.55 \mathrm{VCO}_{2}(\mathrm{l} / \mathrm{min})-3.21$ $\mathrm{VO}_{2}-2.87 \mathrm{n}(\mathrm{g} / \mathrm{min})$ and fat oxidation: $1.67 \mathrm{VO}_{2}$ $(\mathrm{l} / \mathrm{min})-1.67 \mathrm{VCO}_{2}-1.02 n(\mathrm{~g} / \mathrm{min})$, where $n$ is grams of urinary nitrogen per minute calculated from 
urinary carbamide. From the OGTT, the homeostasis model assessment (HOMA) of insulin resistance and the secretion of insulin were calculated (18).

\section{Statistical analyses}

The primary endpoint of this study was the difference in insulin action ( $M$ value) between the LBW and the NBW subjects. Sample size calculation was based on the primary endpoint. Based on the average $M$ value of 9.7 units from a similar group of subjects, S.D. of 2.6 units and with $80 \%$ power to detect a difference of $20 \%$ or more between the birth weight groups, the study required 45 subjects in each group. As the study was planned to include measurements from a second visit after an exercise period, we aimed for 60 subjects per group after adjusting for the possible dropout rate. A two-sided unpaired $t$-test was used to compare means of continuous variables between LBW and NBW subjects. Non-parametric tests were used to compare non-normally distributed variables. The results are reported as mean \pm s.D. $P$ values $\leq 0.05$ were considered statistically significant. When comparing the number of IGT individuals between LBW and NBW subjects, a Fisher's exact test was used. When adjusting for possible confounders, multiple regression analyses were performed. SAS version 9.1 (SAS Institute, Cary, NC, USA) was used for all the statistical analyses.

\section{Results}

The clinical characteristics of the study participants are presented in Table 1 . The LBW subjects were $\sim 1.1 \mathrm{~kg}$

Table 1 Clinical characteristics of the study participants. Unpaired $t$-test was used to examine the differences between LBW and NBW groups. All tests are non-parametric. Values are presented as mean \pm S.D.

\begin{tabular}{lccc}
\hline & $\begin{array}{c}\text { NBW } \\
\text { subjects } \\
(n=56)\end{array}$ & $\begin{array}{c}\text { LBW } \\
\text { subjects } \\
(n=61)\end{array}$ & $\boldsymbol{P}$ value \\
\hline Birth weight (g) & $3215 \pm 122$ & $2115 \pm 246$ & $<0.0001^{*}$ \\
Gestational age (week) & $39.5 \pm 2.1$ & $38.3 \pm 2.8$ & $\mathbf{0 . 0 2}$ \\
Born preterm ( $n)$ & 3 & 13 & - \\
Age (years) & $19.5 \pm 1.1$ & $20 \pm 1.0$ & $\mathbf{0 . 0 0 2}$ \\
Weight (kg) & $55.4 \pm 7$ & $51.9 \pm 9$ & $\mathbf{0 . 0 2}$ \\
Height (cm) & $172 \pm 6.0$ & $167 \pm 6.4$ & $<\mathbf{0 . 0 0 0 1}$ \\
BMl (kg/m $\left.{ }^{2}\right)$ & $19.54 \pm 2.1$ & $19.03 \pm 2.9$ & 0.18 \\
Waist circumference & $71.2 \pm 7.2$ & $69.3 \pm 7.6$ & 0.17 \\
(cm) & & & \\
W/H ratio & $0.83 \pm 0.05$ & $0.83 \pm 0.04$ & 0.52 \\
Triglyceride (mmol/l) & $0.90 \pm 0.4$ & $0.94 \pm 0.5$ & $0.73^{\star}$ \\
Cholesterol (mmol/l) & $3.38 \pm 0.7$ & $3.45 \pm 0.9$ & 0.48 \\
HDL (mmol//) & $0.81 \pm 0.1$ & $0.82 \pm 0.2$ & $0.93^{\star}$ \\
LDL (mmol/l) & $2.1 \pm 0.6$ & $2.1 \pm 0.7$ & $0.59^{\star}$ \\
Systolic BP (mmHg) & $117 \pm 8.5$ & $118 \pm 8.6$ & $0.52^{*}$ \\
Diastolic BP (mmHg) & $75 \pm 6.1$ & $77 \pm 5.6$ & $0.10^{*}$, \\
HbA1c (\%) & $5.4 \pm 0.3$ & $5.3 \pm 0.4$ & 0.44 \\
\hline
\end{tabular}

${ }^{*} P$ values from non-parametric test; ${ }^{\dagger} P=0.01$ when adjusted for height and weight. lighter at birth compared with the NBW group. The LBW men were slightly older, lighter and significantly shorter than the NBW men. After adjustment for the differences in height and weight between LBW and NBW subjects, the diastolic blood pressure (DBP) was significantly higher in the LBW subjects $(P=0.01)$. There was no difference in the BMI or skinfold thickness between the two groups, and in general, all participants were healthy with total cholesterol, LDL-cholesterol and blood pressure measurements within the normal range, except for a mean low HDL-cholesterol level, which was present in both groups and is a common phenomenon in the Indian population (19). In our study, the subjects were not recruited according to gestational age, a factor that has previously been demonstrated to represent a reason for risk (i.e. independent of birth weight) for developing insulin resistance (20). We were subsequently able to obtain the gestational age for 101 individuals, and as seen in Table 1, the LBW group was on average born 1 week earlier and had more preterm births than the NBW group. When subjects born at term alone (excluding preterm subjects) were included in the analyses, similar results were obtained (data not shown). Furthermore, when the analyses were adjusted for gestational age, the results remained similar to that of the unadjusted analysis.

There was no difference in socioeconomic status between the LBW and the NBW group $(P=0.79)$. The LBW subjects had lower protein ingestion and received a lower proportion of their total energy requirement from protein when compared with the NBW subjects (Table 2). This was a feature that was unrelated to their socioeconomic status.

\section{Body composition}

The LBW young men had a significantly reduced total lean body mass (LBM; $P=0.002$ ) and a tendency towards decreased total bone mineral content (BMC; $P=0.1)$. The total fat mass and percentages were similar in the two groups as were the quantity and percentage of truncal fat. However, the ratio of leg fat mass/total fat mass was significantly lower in LBW men $(P=0.03)$, indicating a trend towards an unfavourable fat distribution. When dividing the body into compartments (arm and leg), LBM was reduced in both the arms and the legs $(P=0.002$ and $P=0.006$ respectively), whereas BMC was significantly lower in the arms of the LBW men alone $(P=0.005$; Table 3$)$. Total bone mineral density was similar in both the groups. When adjusted for height and weight in a regression analysis, no significant impact of the birth weight on BMC was observed, supporting the fact that reduced BMC in LBW subjects was associated with a lower height and weight. However, there was no significant difference in LBM between the birth weight groups after adjusting for height and weight $(P=0.12)$. 
Table 2 Dietary intake among LBW and NBW subjects (average daily intake).

\begin{tabular}{lccc}
\hline & NBW $(n=50)$ & LBW $(n=54)$ & $P$ value \\
\hline Energy intake & $2147.3 \pm 362.4$ & $2027.4 \pm$ & 0.11 \\
& & 402.8 & \\
Protein intake & $55.4 \pm 12.0$ & $49.7 \pm 13.7$ & 0.03 \\
Percentage of energy & $10.3 \pm 1.39$ & $9.7 \pm 1.37$ & 0.03 \\
$\quad$ from protein & & & \\
Fat intake & $31.3 \pm 9.7$ & $32.4 \pm 15.0$ & $0.85^{*}$ \\
$\begin{array}{l}\text { Percentage of energy } \\
\text { intake from fat }\end{array}$ & $13.1 \pm 3.4$ & $14.3 \pm 15.0$ & 0.16 \\
$\begin{array}{l}\text { Carbohydrate } \\
\text { Percentage of energy }\end{array}$ & $411.2 \pm 70.5$ & $384.4 \pm 73.5$ & $0.07^{*}$ \\
$\quad$ intake from & $76.6 \pm 3.4$ & $76.1 \pm 5.29$ & $0.78^{*}$ \\
$\quad$ carbohydrate & & & \\
\hline
\end{tabular}

${ }^{*} P$ values from non-parametric test.

\section{Glucose tolerance}

Based on the OGTT, none of the participants were classified as having T2D, though five young men had IGT. Indeed, all subjects with IGT were born with LBW indicating a higher proportion of IGT among LBW subjects when compared with NBW subjects $(P=0.06)$. No significant differences were observed in the mean fasting plasma glucose levels (NBW: $5.02 \pm 0.4$ vs LBW: $5.09 \pm 0.5, P=0.39$ ) or in the mean $2 \mathrm{~h}$ plasma glucose levels (NBW: $5.62 \pm 1.0$ vs LBW: $5.67 \pm 1.5, P=0.82$ ). There were no significant differences in total $\mathrm{AUC}_{120 \mathrm{~min}}$ for glucose $(P=0.31)$, insulin $(P=0.32)$ or $C$-peptide $(P=0.32)$ during the OGTT (Fig. 2).

\section{Insulin resistance and insulin secretion}

No significant difference was observed between LBW and NBW with regard to the peripheral insulin action ( $M$ value; Table 4 ). The HOMA insulin resistance index had a trend towards elevation, though not significant, reflecting potential hepatic insulin resistance among the LBW compared with the NBW subjects $(2.22 \pm 5.3$ vs $1.19 \pm 1.35, P=0.28$ ). Insulin secretion was similar in LBW and NBW men, when expressed as FPIR or related to the glucose level (PHI1). In addition, we did not find any differences when calculating the product of in vivo insulin action and secretion defining the Di between the two groups (Table 4).

\section{Data on the subjects' parents}

Ninety-seven mothers and 76 fathers were willing to participate in the examination. The clinical characteristics of the parents are shown in Table 5. Mothers of LBW subjects weighed less $(P=0.01)$ and were shorter $(P=0.02)$ than mothers of NBW subjects. However, there was no significant difference in the BMI between mothers of LBW and NBW subjects.

Fathers of LBW subjects tended to be shorter when compared with fathers of NBW subjects
(Table 5). There was no significant difference in the parents' glucose tolerance status between the LBW and the NBW groups (data not shown). As the parents of LBW subjects tended to be smaller, we performed a sub-analysis with LBM and final height as response variables with adjustments for parental height. After adjusting for parental height, there was a trend showing that paternal height $(P=0.06)$ and birth weight $(P=0.06)$ were associated with the LBM of the offspring. Both maternal $(P=0.003)$ and paternal $(P=0.02)$ height had a significant impact on the height of the offspring indicating a potential intergenerational impact, whereas the influence of birth weight was no longer statistically significant after adjustment for parental height.

\section{Discussion}

To our knowledge, this is the first study in ethnic rural adult Indians in which body composition in LBW and NBW subjects was assessed using DEXA scans, and in vivo metabolism studied using state-of-the-art hyperinsulinaemic euglycaemic clamps combined with IVGTT and indirect calorimetry. The LBW young men were characterised by i) shorter adult height, ii) lower adult weight, iii) lower LBM, iv) lower ratio of leg fat mass/total fat mass, v) an elevated risk for developing IGT, vi) increased DBP, and vii) no significant defects of whole body in vivo insulin action or secretion compared with young men with NBW.

The LBW subjects had a lower final height when compared with NBW subjects, as has been previously described among Caucasian subjects $(21,22)$. The reduced final height in adults is associated with an increase in $2 \mathrm{~h}$ post-OGTT plasma glucose levels (23) and middle-aged men with IGT are 3-4 $\mathrm{cm}$ shorter than

Table 3 Results from DEXA scan of body composition. Data are presented as mean \pm S.D.

\begin{tabular}{lccc}
\hline & $\begin{array}{c}\text { NBW } \\
\text { subjects } \\
(n=52)\end{array}$ & $\begin{array}{c}\text { LBW } \\
\text { subjects } \\
(n=55)\end{array}$ & $\boldsymbol{P}$ value \\
\hline Fat mass total $(\mathrm{kg})$ & $8.3 \pm 3.6$ & $7.7 \pm 5.1$ & $0.49^{\star}$ \\
Lean mass total $(\mathrm{kg})$ & $45.0 \pm 4.5$ & $42.1 \pm 5.4$ & $\mathbf{0 . 0 0 2}$ \\
Lean mass arm (kg) & $2.7 \pm 0.3$ & $2.5 \pm 0.3$ & $\mathbf{0 . 0 0 2}$ \\
Lean mass leg (kg) & $7.6 \pm 0.9$ & $7.1 \pm 1.1$ & $\mathbf{0 . 0 0 6}$ \\
BMC total (g) & $2211 \pm 247$ & $2123 \pm 308$ & $\mathbf{0 . 1 0}$ \\
BMC arm & $164 \pm 22$ & $152 \pm 22$ & $\mathbf{0 . 0 0 5}$ \\
BMC leg & $413 \pm 53$ & $397 \pm 75$ & 0.21 \\
BMD total & $1.10 \pm 0.08$ & $1.11 \pm 0.09$ & 0.45 \\
Fat \% total & $14.5 \pm 4.7$ & $14.0 \pm 6.0$ & $0.16^{\star}$ \\
Fat \% trunk & $12.6 \pm 5.0$ & $12.3 \pm 6.5$ & $0.25^{\star}$ \\
Trunk FM/total FM (g) & $0.39 \pm 0.05$ & $0.39 \pm 0.05$ & 0.70 \\
Leg FM/total FM (g) & $0.20 \pm 0.02$ & $0.19 \pm 0.03$ & $\mathbf{0 . 0 3}$ \\
Trunk FM/leg FM (\%) & $0.76 \pm 0.14$ & $0.81 \pm 0.19$ & 0.14 \\
Total lean/total mass (g) & $81.5 \pm 4.5$ & $81.9 \pm 5.7$ & $0.18^{\star}$ \\
\hline
\end{tabular}

${ }^{*} P$ value from non-parametric test. BMC, bone mineral content; BMD, bone mineral density; FM, fat mass. 

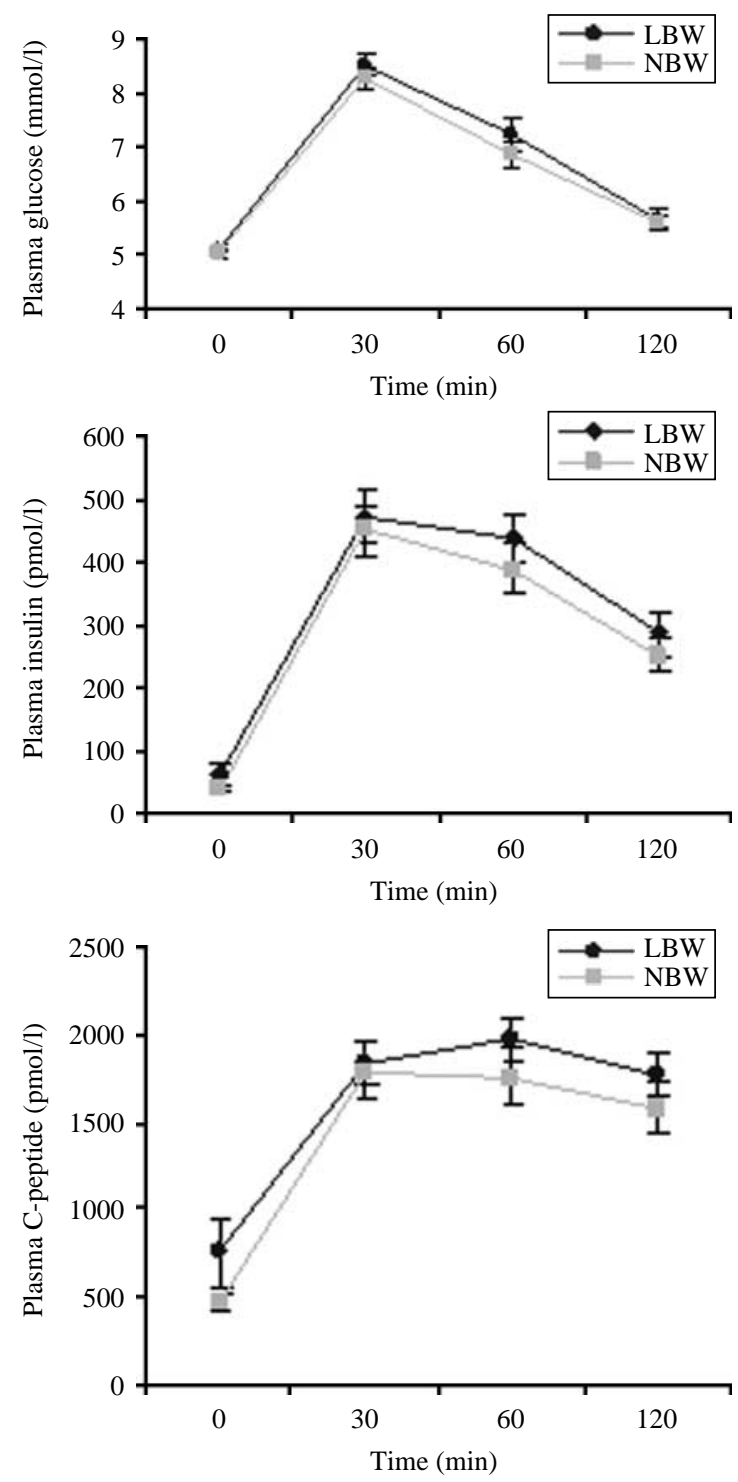

Figure 2 Plasma glucose, insulin and C-peptide during an OGTT. Data are presented as mean \pm S.E.M.

a control group with normal glucose tolerance matched for sex, age and BMI (24). Thus, the lower final height in our LBW Indian subjects may represent a predisposing factor for developing glucose intolerance and perhaps T2D later in life. Our finding of a reduced LBM in LBW subjects had previously been reported by other groups $(25,26)$. A low LBM has been associated with increased mortality (27), and among elderly Oriental Asians, LBM was a better predictor of mortality than BMI (28). Furthermore, as muscle is a very important site for insulin-stimulated glucose uptake, the reduced LBM detected in the LBW subjects may potentially lead to insulin resistance later in life. When adjusting for current weight and height, the impact of birth weight was weakened, suggesting that a reduced height is one of the main outcomes of an adverse intrauterine environment, along with a reduced LBM as a potential secondary effect.

HOMA insulin resistance, which is mainly supposed to represent hepatic insulin action, tended to be higher in LBW subjects, supporting similar studies on western LBW subjects (29). No differences in peripheral insulin resistance or insulin secretion were observed between the LBW and the NBW subjects. This may be explained by the fact that these young men were still living in their indigenous environment, which appears to be metabolically conducive and in continuum with the environment the subjects had experienced in utero. Thus, according to the thrifty phenotype hypothesis (30), the metabolic effects of foetal programming may only become detrimental after birth in postnatal or adult life, when the subject's current environment and living conditions differ and are apparently more affluent than those of their mothers during foetal life, with reference to energy intake and metabolism. Indeed, the young Indian men included in this study still live in a typically rural habitat and have rather low BMIs and waist circumferences. Thus, the impact of a 'Western' transition in lifestyle may not have appeared as yet, or alternatively, the metabolic abnormalities may be unmasked later with the progression of their age.

The finding of a lack of difference in whole body insulin sensitivity and insulin secretion as measured by the hyperinsulinaemic euglycaemic clamp technique seems to suggest that whole body insulin resistance and/or defective insulin secretion may not be the primary determinants of the association between LBW and later development of T2D, at least in this group of male subjects in early adulthood. In Danish Caucasian cohorts, who have been recruited with methods similar to this study, we have observed increased levels of fasting blood glucose and insulin, hepatic insulin resistance and lower insulin-stimulated rate of glycolytic flux, relatively reduced insulin secretion when insulin sensitivity was accounted for and an increased rate of whole body lipolysis in LBW subjects $(21,22,29)$. While in vivo lipolysis and glycolytic flux were not measured in this study, the apparently more conserved metabolic phenotype among Indian LBW subjects with normal fasting plasma glucose levels may be explained by a lower BMI $\left(19 \mathrm{~kg} / \mathrm{m}^{2}\right)$ compared with that of the previously studied Danish LBW subjects (average BMI $23 \mathrm{~kg} / \mathrm{m}^{2}$ ).

At the molecular level, we have shown that young men who were born with LBW exhibit multiple abnormalities in the insulin-signalling pathways in skeletal muscle and adipose tissue $(31,32)$. Owing to local ethical considerations, we did not perform muscle and fat biopsies in this study to examine the molecular metabolic alterations in the Indian cohort.

Obesity, and particularly abdominal obesity, i.e. visceral fat, is associated with insulin resistance among both Caucasians and Asian Indians $(33,34)$. 
Table 4 Results from hyperinsulinaemic euglycaemic clamp, indirect calorimetry and IVGTT. Values are presented as mean \pm S.D.

\begin{tabular}{lccc}
\hline & $\begin{array}{c}\text { NBW } \\
\text { subjects } \\
(n=56)\end{array}$ & $\begin{array}{c}\text { LBW } \\
\text { subjects } \\
(n=59)\end{array}$ & P value \\
\hline Basal p-glucose (mmol/l) & $4.71 \pm 0.36$ & $4.74 \pm 0.44$ & 0.73 \\
Basal p-insulin (pmol/l) & $24.7 \pm 17.7$ & $32.0 \pm 37$ & $0.18^{*}$ \\
$M$ value (mg/kg FFM per min) & $10.46 \pm 3.8$ & $10.34 \pm 3.8$ & 0.86 \\
$M$ value (mg/total mass per min) & $8.64 \pm 3.28$ & $8.59 \pm 3.41$ & 0.95 \\
RQ basal & $0.80 \pm 0.08$ & $0.81 \pm 0.07$ & 0.48 \\
RQ insulin stimulated & $0.90 \pm 0.07$ & $0.90 \pm 0.06$ & 0.82 \\
GOX basal (mg/kg FFM per min) & $1.96 \pm 1.7$ & $2.25 \pm 1.48$ & 0.49 \\
GOX insulin stimulated & $4.65 \pm 1.3$ & $4.78 \pm 1.5$ & 0.68 \\
(mg/kg FFM per min) & & & \\
FOX basal (mg/kg FFM per min) & $1.78 \pm 0.86$ & $1.70 \pm 0.75$ & 0.70 \\
FOX insulin stimulated & $0.94 \pm 0.63$ & $0.94 \pm 0.62$ & 0.99 \\
$\quad$ (mg/kg FFM per min) & & & \\
NOGM (mg/kg FFM per min) & $5.92 \pm 3.3$ & $6.17 \pm 3.6$ & 0.74 \\
AUC insulin $0-10$ & $3460 \pm 1841$ & $3276 \pm 2224$ & 0.65 \\
AUC glucose $0-10$ & $113.9 \pm 15.8$ & $113.0 \pm 18$ & 0.77 \\
PHI-1 & $30.4 \pm 16.2$ & $28.9 \pm 18.3$ & 0.66 \\
FPIR (pmol/l) & $3210 \pm 1765$ & $2985 \pm 2094$ & 0.56 \\
Di & $292 \pm 197$ & $262 \pm 152$ & 0.40 \\
\hline
\end{tabular}

${ }^{*} P$ values from non-parametric test. $M$ value, insulin-stimulated glucose uptake; GOX, glucose oxidation (4.55 $\mathrm{VCO}_{2}(1 / \mathrm{min})-3.21 \mathrm{VO}_{2}(\mathrm{l} / \mathrm{min})-2.87$ $n(\mathrm{~g} / \mathrm{min}), n$ calculated from urinary carbamide); $\mathrm{FOX}$, fat oxidation $1.67 \mathrm{VO}_{2}$ $(1 / \mathrm{min})-1.67 \mathrm{VCO}_{2}(1 / \mathrm{min})-1.92 n(\mathrm{~g} / \mathrm{min}) ;$ GOX basal $n=53$, GOX insulin $n=75$, FOX basal $n=53$ FOX insulin $n=75$; NOGM, nonoxidative glucose metabolism (M-GOX); PHI-1, AUC insulin $_{\text {/ }}$ UC $_{\text {glucose }}$; FPIR, calculated as the incremental AUC insulin ${ }_{0-10}$ from IVGTT.

Caucasian LBW subjects have more abdominal fat and less leg fat than NBW subjects (21). Similarly, we found a lower ratio of leg fat mass/total fat mass. As lower body fat is perceived to be protective of insulin resistance (35), this altered fat distribution may theoretically be unfavourable for metabolic control over time. Interestingly, the association between birth weight and adiposity only seems to exist for relative adiposity, and not for fat percentages or absolute amount per se (25). Small Indian babies have previously been named 'thinfat' babies, due to the low muscle mass and preservation of body fat during their intrauterine development (10). We have confirmed the presence of a lower muscle mass at the age of 20 years, though without an increase in the fat mass or total fat percentages in the LBW subjects. This may be due to the fact that they had a rather low BMI at the time of evaluation. Therefore, it remains to be seen whether the changes would become manifest later in life.

The presence of a lower BMC in our LBW subjects is in accordance with a previous finding in a Finnish cohort (36). However, no significant differences in the bone mineral density between LBW and NBW were observed, suggesting that the lower BMC may be due to the lower height of LBW subjects. Our findings of an inverse association between birth weight and blood pressure are consistent with the results from a recent review (37). Elevated blood pressure represents a hallmark of the metabolic syndrome and is a significant independent risk factor of CVD mortality (38).

We had detected five subjects with IGT in this study sample, which corresponded with a prevalence of $\sim 5 \%$ and resembled the findings of previous studies $(39,40)$. Interestingly, all five subjects were born with LBW, supporting the idea that LBW subjects are at a higher risk of developing T2D.

Parental glucose tolerance is known to be associated with the metabolic outcome in the offspring (41). However, in this study, the glucose tolerance status was similar among parents with LBW and NBW offspring, thus the metabolic differences between LBW and NBW subjects found in this study cannot be explained by the glucose tolerance status of the parents alone but may be explained by birth weight per se.

As mothers of the LBW subjects were shorter than those of the NBW subjects, we adjusted our analyses for parental height and found that the associations between birth weight on one side and a reduced LBM and height on the other side were weakened. This suggests that an intergenerational effect is probably being transmitted and potentially (though not proven) genetic features may influence the association between LBW and risk of T2D. The extent to which LBW due to genetic as opposed to non-genetic causes is associated with the risk of T2D and associated states of disease later in life are much discussed issues. Nevertheless, the underlying

Table 5 Clinical characteristics of the parents. LBW and NBW refers to their sons' birth weights.

\begin{tabular}{|c|c|c|c|c|c|c|}
\hline & \multicolumn{2}{|c|}{ Mother } & \multirow[b]{2}{*}{$P$ value } & \multicolumn{2}{|c|}{ Father } & \multirow[b]{2}{*}{$P$ value } \\
\hline & LBW $(n=49)$ & NBW $(n=48)$ & & LBW $(n=36)$ & $\operatorname{NBW}(n=40)$ & \\
\hline Age (years) & $43.5 \pm 5.0$ & $43.3 \pm 5.2$ & 0.86 & $51.0 \pm 7.5$ & $53.2 \pm 6.3$ & $0.10^{*}$ \\
\hline Weight (kg) & $51.8 \pm 12.1$ & $57.7 \pm 11.1$ & 0.01 & $57.6 \pm 10.3$ & $60.3 \pm 10.1$ & 0.25 \\
\hline Height $(m)$ & $1.51 \pm 0.06$ & $1.54 \pm 0.05$ & $0.02^{\star}$ & $1.64 \pm 0.07$ & $1.66 \pm 0.05$ & 0.12 \\
\hline BMI $\left(\mathrm{kg} / \mathrm{m}^{2}\right)$ & $22.8 \pm 5.4$ & $24.4 \pm 4.8$ & 0.12 & $21.5 \pm 3.4$ & $22.0 \pm 3.7$ & 0.54 \\
\hline W/H ratio & $0.89 \pm 0.07$ & $0.90 \pm 0.08$ & 0.53 & $0.96 \pm 0.06$ & $0.97 \pm 0.06$ & $0.36^{*}$ \\
\hline $\mathrm{TG}(\mathrm{mmol} / \mathrm{l})$ & $1.46 \pm 0.85$ & $1.30 \pm 0.80$ & $0.28^{\star}$ & $1.87 \pm 1.42$ & $1.63 \pm 1.15$ & $0.70^{\star}$ \\
\hline $\begin{array}{c}\text { Cholesterol } \\
(\mathrm{mmol} / \mathrm{l})\end{array}$ & $4.71 \pm 0.98$ & $4.66 \pm 0.88$ & 0.85 & $4.74 \pm 0.98$ & $4.56 \pm 0.91$ & 0.36 \\
\hline $\mathrm{HDL}(\mathrm{mmol} / \mathrm{l})$ & $1.01 \pm 0.22$ & $1.01 \pm 0.19$ & $0.85^{\star}$ & $0.98 \pm 0.18$ & $0.94 \pm 0.18$ & 0.42 \\
\hline $\mathrm{LDL}(\mathrm{mmol} / \mathrm{l})$ & $2.87 \pm 0.78$ & $2.85 \pm 0.75$ & 0.86 & $2.82 \pm 0.82$ & $2.69 \pm 0.73$ & 0.52 \\
\hline
\end{tabular}

${ }^{*} P$ values from non-parametric test. 
idea of the Barker hypothesis is that an adverse foetal environment, and thus a non-genetic LBW phenotype, is the main risk factor of T2D later in life. Accordingly, we cannot totally exclude the possibility that LBW among Indians if genetic in origin may not necessarily represent the same significant risk factor of T2D as among non-Indians with LBW due to non-genetic causes. In our study, LBW seemed to occur with an equal frequency amongst the lower and higher socioeconomic classes of the population. This indicates that antenatal nutrition may not have been largely different between the two socioeconomic classes. However, the study was not adequately powered to provide a sufficient answer to this question.

The major strength of this study is that comprehensive physiological methods have been applied in an ethnically homogeneous group in a rural part of India consisting of a large cohort of young men born with LBW and age-matched NBW controls. However, we are aware of the limitations including the lack of childhood growth due to associated malnutrition and we may therefore be unable to disentangle the effect of intrauterine growth from that of early childhood growth. The study was designed to compare two groups that had significantly different birth weights. Hence, the 'normal' birth weight group may have had a significantly higher birth weight when compared with the median birth weight of the south Indian population.

In summary, LBW among rural Indians is associated with only subtle risk factors of T2D and cardiovascular disease including a lowered adult height and LBM, altered body fat distribution, increased risk of IGT and a minor elevation of the DBP. We did not find any significant difference in whole-body insulin resistance or in insulin secretion between the two groups. A longterm follow-up of these subjects will be required to determine whether more severe dysmetabolic traits will occur among the rural Indian LBW subjects with time or age, or in some of the LBW subjects when potentially exposed later to a more affluent Western environment.

\section{Declaration of interest}

The authors declare that there is no conflict of interest that could be perceived as prejudicing the impartiality of the research reported.

\section{Funding}

This work was supported by The Danish Strategic Research Council and Biocampus, University of Copenhagen. The funders had no role in study design, data collection and analysis, decision to publish or preparation of the manuscript.

\section{Author contribution statement}

N Thomas, L G Grunnet, P Poulsen, A Vaag and Ib C Bygbjerg contributed to conception and design, analyses and interpretation of data and also helped in revising, drafting, improving the final version and final approval of the manuscript. S Christopher, R Spurgeon, M Inbakumari, R Livingstone, R Alex, V R Mohan, B Antonisamy, F S
Geethanjali and R Karol contributed to collection, analysis and interpretation of data, revision and final approval of the manuscript.

\section{Acknowledgements}

We thank Jayaprakash Mulilyil, B Elizabeth, Sheeba Paul, Harsha Karanchi, Shanthveer Gangu, L N Babu and Lars Sander Koch for providing excellent technical support and assistance with the experiments. We would like to thank Ms Banu for her secretarial support.

\section{References}

1 Wild S, Roglic G, Green A, Sicree R \& King H. Global prevalence of diabetes: estimates for the year 2000 and projections for 2030 . Diabetes Care 200427 1047-1053. (doi:10.2337/diacare.27.5. 1047)

2 Das UN. Nutritional deficiencies and the prevalence of syndrome $\mathrm{X}$ in south Asians. Nutrition 200218 282. (doi:10.1016/S08999007(01)00741-9)

3 Yajnik CS. The insulin resistance epidemic in India: fetal origins, later lifestyle, or both? Nutrition Reviews 200159 1-9. (doi:10. 1111/j.1753-4887.2001.tb01898.x)

4 Liew CF, Seah ES, Yeo KP, Lee KO \& Wise SD. Lean, nondiabetic Asian Indians have decreased insulin sensitivity and insulin clearance, and raised leptin compared to Caucasians and Chinese subjects. International Journal of Obesity and Related Metabolic Disorders 200327 784-789. (doi:10.1038/sj.ijo.0802307)

5 Raji A, Gerhard-Herman MD, Warren M, Silverman SG, Raptopoulos V, Mantzoros CS \& Simonson DC. Insulin resistance and vascular dysfunction in nondiabetic Asian Indians. Journal of Clinical Endocrinology and Metabolism 200489 3965-3972. (doi:10.1210/jc.2004-0087)

6 Chandalia M, Lin P, Seenivasan T, Livingston EH, Snell PG, Grundy SM \& Abate N. Insulin resistance and body fat distribution in south Asian men compared to Caucasian men. PLOS ONE 2007 2 e812. (doi:10.1371/journal.pone.0000812)

7 Petersen KF, Dufour S, Feng J, Befroy D, Dziura J, Dalla MC, Cobelli C \& Shulman GI. Increased prevalence of insulin resistance and nonalcoholic fatty liver disease in Asian-Indian men. PNAS 2006103 18273-18277. (doi:10.1073/pnas.0608537103)

8 Whincup PH, Kaye SJ, Owen CG, Huxley R, Cook DG, Anazawa S, Barrett-Connor E, Bhargava SK, Birgisdottir BE, Carlsson S, de Rooij SR, Dyck RF, Eriksson JG, Falkner B, Fall C, Forsen T, Grill V, Gudnason V, Hulman S, Hypponen E, Jeffreys M, Lawlor DA, Leon DA, Minami J, Mishra G, Osmond C, Power C, Rich-Edwards JW, Roseboom TJ, Sachdev HS, Syddall H, Thorsdottir I, Vanhala M, Wadsworth M \& Yarbrough DE. Birth weight and risk of type 2 diabetes: a systematic review. Journal of the American Medical Association 2008300 2886-2897. (doi:10. 1001/jama.2008.886)

9 Yajnik CS. Nutrient-mediated teratogenesis and fuel-mediated teratogenesis: two pathways of intrauterine programming of diabetes. International Journal of Gynaecology and Obstetrics 2009 104 (Suppl 1) S27-S31. (doi:10.1016/j.ijgo.2008.11.034)

10 Yajnik CS, Fall CHD, Coyaji KJ, Hirve SS, Rao S, Barker DJP, Joglekar C \& Kellingray S. Neonatal anthropometry: the thin-fat Indian baby. The Pune Maternal Nutrition Study. International Journal of Obesity and Related Metabolic Disorders 200327 173180. (doi:10.1038/sj.ijo.802219)

11 Ramakrishnan G, Unni US, Raj T, Thomas T, Vaz M \& Kurpad AV. A pilot study on hyperinsulinaemic euglycaemic clamp based insulin sensitivity in young adult Indian males with low body mass index. Indian Journal of Medical Research 2009129 409-417.

12 Majumder PP. People of India. Biological diversity and affinities. Evolutionary Anthropology $1998 \quad 6 \quad 100-110$. (doi:10.1002/ (SICI)1520-6505(1998)6:3 < 100::AID-EVAN4> 3.0.CO;2-I) 
13 Mohan VR \& Muliyil J. Mortality patterns and the effect of socioeconomic factors on mortality in rural Tamil Nadu, south India: a community-based cohort study. Transactions of the Royal Society of Tropical Medicine and Hygiene 2009103 801-806. (doi:10.1016/j.trstmh.2009.04.014)

14 DeFronzo RA, Tobin JD \& Andres R. Glucose clamp technique: a method for quantifying insulin secretion and resistance. American Journal of Physiology 1979237 E214-E223.

15 Aykroyd WR, Gopalan C \& Balasubramanium SC. The Nutritive Value of Indian foods and the planning of satisfactory diets. Special Report Series - Indian Council of Medical Research 196342 1-255.

16 Kahn SE, Prigeon RL, McCulloch DK, Boyko EJ, Bergman RN, Schwartz MW, Neifing JL, Ward WK, Beard JC \& Palmer JP. Quantification of the relationship between insulin sensitivity and beta-cell function in human subjects. Evidence for a hyperbolic function. Diabetes 199342 1663-1672. (doi:10.2337/diabetes. 42.11.1663)

17 Frayn KN. Calculation of substrate oxidation rates in vivo from gaseous exchange. Journal of Applied Physiology 198355 628-634.

18 Matthews DR, Hosker JP, Rudenski AS, Naylor BA, Treacher DF \& Turner RC. Homeostasis model assessment: insulin resistance and beta-cell function from fasting plasma glucose and insulin concentrations in man. Diabetologia 198528 412-419. (doi:10. 1007/BF00280883)

19 Tai ES, Emmanuel SC, Chew SK, Tan BY \& Tan CE. Isolated low HDL cholesterol: an insulin-resistant state only in the presence of fasting hypertriglyceridemia. Diabetes $1999 \mathbf{4 8}$ 1088-1092. (doi:10.2337/diabetes.48.5.1088)

20 Hofman PL, Regan F, Jackson WE, Jefferies C, Knight DB, Robinson EM \& Cutfield WS. Premature birth and later insulin resistance. New England Journal of Medicine 20043512179 2186. (doi:10.1056/NEJMoa042275)

21 Brons C, Jensen CB, Storgaard H, Alibegovic A, Jacobsen S, Nilsson E, Astrup A, Quistorff B \& Vaag A. Mitochondrial function in skeletal muscle is normal and unrelated to insulin action in young men born with low birth weight. Journal of Clinical Endocrinology and Metabolism 200893 3885-3892. (doi:10. 1210/jc.2008-0630)

22 Jensen CB, Storgaard H, Dela F, Holst JJ, Madsbad S \& Vaag AA. Early differential defects of insulin secretion and action in 19-yearold caucasian men who had low birth weight. Diabetes 200251 1271-1280. (doi:10.2337/diabetes.51.4.1271)

23 Faerch K, Vaag A, Witte DR, Jorgensen T, Pedersen O \& BorchJohnsen K. Predictors of future fasting and 2-h post-OGTT plasma glucose levels in middle-aged men and women-the Inter99 study. Diabetic Medicine 200926 377-383. (doi:10.1111/j.1464-5491. 2009.02688.x)

24 Brown DC, Byrne CD, Clark PM, Cox BD, Day NE, Hales CN, Shackleton JR, Wang TW \& Williams DR. Height and glucose tolerance in adult subjects. Diabetologia 199134 531-533. (doi:10.1007/BF00403292)

25 Rogers I. The influence of birthweight and intrauterine environment on adiposity and fat distribution in later life. International Journal of Obesity and Related Metabolic Disorders 200327 755777. (doi:10.1038/sj.ijo.0802316)

26 Singhal A, Wells J, Cole TJ, Fewtrell M \& Lucas A. Programming of lean body mass: a link between birth weight, obesity, and cardiovascular disease? American Journal of Clinical Nutrition $200377726-730$.

27 Heitmann BL, Erikson H, Ellsinger BM, Mikkelsen KL \& Larsson B. Mortality associated with body fat, fat-free mass and body mass index among 60-year-old swedish men - a 22-year follow-up. The study of men born in 1913. International Journal of Obesity and Related Metabolic Disorders 200024 33-37. (doi:10.1038/sj.ijo. 0801082)
28 Han SS, Kim KW, Kim KI, Na KY, Chae DW, Kim S \& Chin HJ. Lean mass index: a better predictor of mortality than body mass index in elderly Asians. Journal of the American Geriatrics Society 201058 312-317. (doi:10.1111/j.1532-5415.2009.02672.x)

29 Alibegovic AC, Hojbjerre L, Sonne MP, van Hall G, Alsted TJ, Kiens B, Stallknecht B, Dela F \& Vaag A. Increased rate of whole body lipolysis before and after 9 days of bed rest in healthy young men born with low birth weight. American Journal of Physiology. Endocrinology and Metabolism 2010298 E555-E564. (doi:10. 1152/ajpendo.00223.2009)

30 Hales CN \& Barker DJ. The thrifty phenotype hypothesis. British Medical Bulletin 200160 5-20. (doi:10.1093/bmb/60.1.5)

31 Ozanne SE, Jensen CB, Tingey KJ, Storgaard H, Madsbad S \& Vaag AA. Low birthweight is associated with specific changes in muscle insulin-signalling protein expression. Diabetologia 200548 547-552. (doi:10.1007/s00125-005-1669-7)

32 Ozanne SE, Jensen CB, Tingey KJ, Martin-Gronert MS, Grunnet L, Brons C, Storgaard H \& Vaag AA. Decreased protein levels of key insulin signalling molecules in adipose tissue from young men with a low birthweight: potential link to increased risk of diabetes? Diabetologia 200649 2993-2999. (doi:10.1007/s00125-0060466-2)

33 Banerji MA, Faridi N, Atluri R, Chaiken RL \& Lebovitz HE. Body composition, visceral fat, leptin, and insulin resistance in Asian Indian men. Journal of Clinical Endocrinology and Metabolism 1999 84 137-144. (doi:10.1210/jc.84.1.137)

34 Bergman RN, Kim SP, Catalano KJ, Hsu IR, Chiu JD, Kabir M, Hucking K \& Ader M. Why visceral fat is bad: mechanisms of the metabolic syndrome. Obesity 200614 (Suppl 1) 16S-19S. (doi:10. 1038/oby.2006.277)

35 Snijder MB, Dekker JM, Visser M, Bouter LM, Stehouwer CD, Yudkin JS, Heine RJ, Nijpels G, Seidell JC \& Hoorn S. Trunk fat and leg fat have independent and opposite associations with fasting and postload glucose levels: the Hoorn study. Diabetes Care 2004 27 372-377. (doi:10.2337/diacare.27.2.372)

36 Laitinen J, Kiukaanniemi K, Heikkinen J, Koiranen M, Nieminen P, Sovio U, Keinänen-Kiukaanniemi S \& Järvelin M. Body size from birth to adulthood and bone mineral content and density at 31-years of age: results from the northern Finland 1966 birth cohort study. Osteoporosis International 200516 1417-1424. (doi:10.1007/s00198-005-1857-9)

37 Huxley RR, Shiell AW \& Law CM. The role of size at birth and postnatal catch-up growth in determining systolic blood pressure: a systematic review of the literature. Journal of Hypertension 2000 18 815-831. (doi:10.1097/00004872-200018070-00002)

$38 \mathrm{Gu}$ Q, Burt VL, Paulose-Ram R, Yoon S \& Gillum RF. High blood pressure and cardiovascular disease mortality risk among U.S. adults: the third National Health and Nutrition Examination Survey mortality follow-up study. Annals of Epidemiology $2008 \mathbf{1 8}$ 302-309. (doi:10.1016/j.annepidem.2007.11.013)

39 Raghupathy P, Antonisamy B, Geethanjali FS, Saperia J, Leary SD, Priya G, Richard J, Barker DJ \& Fall CH. Glucose tolerance, insulin resistance and insulin secretion in young south Indian adults: relationships to parental size, neonatal size and childhood body mass index. Diabetes Research and Clinical Practice 201087 283-292. (doi:10.1016/j.diabres.2009.11.015)

40 Ramachandran A, Snehalatha C, Dharmaraj D \& Viswanathan M. Prevalence of glucose intolerance in Asian Indians. Urban-rural difference and significance of upper body adiposity. Diabetes Care 199215 1348-1355. (doi:10.2337/diacare.15.10.1348)

41 Meigs JB, Cupples LA \& Wilson PW. Parental transmission of type 2 diabetes: the Framingham Offspring Study. Diabetes $2000 \mathbf{4 9}$ 2201-2207. (doi:10.2337/diabetes.49.12.2201)

Received 6 October 2011

Revised version received 9 January 2012

Accepted 16 January 2012 